\title{
Synthesis of a novel hybrid metal-organic salt and its solid-state transformation $\dagger$
}

\author{
Javier Martí-Rujas*a and Massimo Cametti ${ }^{\mathrm{b}}$
}

\begin{abstract}
A new non-centrosymmetric adamantanoid metal cluster has been synthesized by combining the macrocyclic $\mathrm{K} 222$ cryptand and $\mathrm{ZnI}_{2}$. Its solid-state crystal-to-polycrystalline transformation involves only the anionic adamantanoid cluster, while the cationic cryptand remains virtually unchanged as shown by single crystal and powder X-ray crystallography.
\end{abstract}

Chemical reactivity in the solid state is an interesting research field and its understanding is quite underdeveloped, especially if compared to the solution state. ${ }^{1}$ Hybrid metal-organic salts built by a network of weak hydrogen bonding interactions are one type of solids that display various interesting properties. ${ }^{2}$ Particularly, in the solid state hydrogen bonding metal-organic salts have shown potential applications in areas such as gas adsorption, ${ }^{3}$ separation, ${ }^{4}$ and for their magnetic properties. ${ }^{5}$ The retention of crystallinity of such hybrid metal organic salts is crucial to visualize the structural changes taking place in the solid-state.

Solid state reactivity of metal-organic complexes has been focused mainly on small ligands containing nitrogen bases showing the conversion from salt complexes into coordination networks and vice versa. ${ }^{6}$ Only recently larger organic ligands have been investigated via mechanochemical dehydrochlorination reactions. ${ }^{7}$ Macrocyclic K222, in addition, received attention in the synthesis of hybrid metal-organic complexes. ${ }^{8}$ However, the structural reactivity of complexes involving $\mathrm{K} 222$ and tetrahalide counterions has received less attention. Typically, solid-state reactions of porous hybrid metal-organic complexes are guest inclusion-release processes that tend to occur via single-crystal-to-single-crystal

\footnotetext{
${ }^{a}$ Center for Nano Science and Technology@Polimi, Istituto Italiano di Tecnologia, Via Pascoli 70/3, 20133 Milano, Italy. E-mail: javier.rujas@iit.it; Tel: +390223999829

${ }^{b}$ Department of Chemistry, Materials and Chemical Engineering “Giulio Natta", Politecnico di Milano, Via L. Mancinelli 7, 20131 Milan, Italy

$\dagger$ Electronic supplementary information (ESI) available. CCDC 948435 (1), 948434 (2), 948436 (3), contain supplementary crystallographic data for this paper.
}

pathways without altering the host framework. However, in non-porous metal-organic complexes reactions occurring either with metal anions and/or organic cations usually proceed by disrupting single crystallinity due to the lack of voids along which molecules can diffuse. As a result, often interesting reactions are left unexplored, particularly reactions involving large structural transformations.

In this work, by combining macrocyclic $\mathrm{K} 222$ and $\mathrm{ZnI}_{2}$, we have obtained a crystalline material of formula $\left[\mathrm{K} 222-\mathrm{H}_{2}\right]^{2+}$ $\left[\mathrm{Zn}_{4}(\mathrm{MeO})_{6} \mathrm{I}_{4}\right]^{2-} \cdot\left(\mathrm{H}_{2} \mathrm{O}\right)$ (1) which is constituted by a doubly protonated $\mathrm{K} 222$ dication and a dianionic adamantanoid metal cluster, crystallizing in the non-centrosymmetric space group $P 2_{1} 3$ (Scheme 1a). Although several structures containing adamantanoid metal clusters can be found in the literature, ${ }^{9}$ to the best of our knowledge, compound 1 represents the first d-block metal cluster with adamantanoid topology containing $\mu$-oxygen atoms. ${ }^{10} \mathrm{We}$ also report, for the first time, the solidstate transformation of $\mathbf{1}$ into a trigonal complex of formula

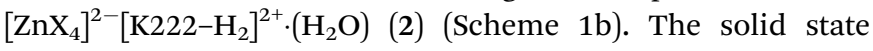

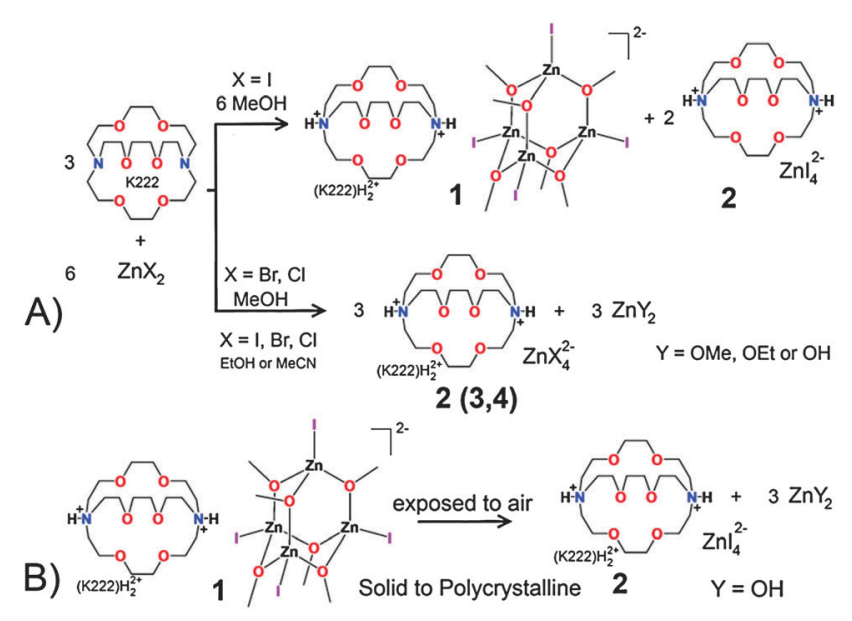

Scheme 1 Synthesis of complex salts 1-4 (a) and the solid-state conversion of 1 into 2 (b) 
reaction occurs via a single-crystal-to-polycrystalline transformation which involves major anionic structural changes. The structural analysis has been carried out combining single crystal and powder $\mathrm{X}$-ray diffraction. Interestingly, the adamantanoid metal cluster only forms with the iodide salt, while bromide and chloride $\mathrm{Zn}$ metal salts only form the trigonal phase (Scheme 1).

Complex 1 was prepared by mixing a solution of K222 in $(\mathrm{MeOH} ; 1 \mathrm{ml})$ and $\mathrm{ZnI}_{2}(\mathrm{MeOH} ; 1 \mathrm{ml})$ in a $1: 2$ molar ratio (0.053 mmol: $0.106 \mathrm{mmol}$ ). The $\mathrm{ZnI}_{2}$ solution was added dropwise, and after 1 day colorless block crystals suitable for single crystal $\mathrm{X}$-ray analysis were obtained. $\neq^{11} \mathrm{X}$-ray crystallography demonstrated that 1 crystallizes in the cubic non-centrosymmetric space group $P 2_{1} 3$ (198) with the formula $\left[\mathrm{Zn}_{4}(\mathrm{MeO})_{6} \mathrm{I}_{4}\right]^{2-}\left[\mathrm{K} 222-\mathrm{H}_{2}\right]^{2+} \cdot\left(\mathrm{H}_{2} \mathrm{O}\right)$. The crystal structure of the complex salt 1 is shown in Fig. $1 .^{12}$ In 1, K222 is doubly-protonated and adopts the endo-endo type conformation where the $\mathrm{N}$ atoms are directed towards the cavity of the macrocycle (Fig 1a). Likewise, the $O$ atoms point inwards the inner cavity of the macrocycle where weak $\mathrm{N}^{+}-\mathrm{H} \cdots \mathrm{O}$ hydrogen bond interactions are observed. The nonbonding $\mathrm{N}$. . N separation (6.124(9) $\mathrm{A}$ ) is markedly shorter than that of the neutral cryptand (6.871(4) $\AA$ ). ${ }^{13}$

The dianion adamantanoid is formed by four $\mathrm{Zn}$ metal centers located at the vertices of a tetrahedron in which each metal is tetrahedrally coordinated by three $\mathrm{O}$ atoms, from deprotonated methanol molecules, and one I atom. The four assembled $\mathrm{Zn}$ metal centers give rise to three fused hexagonal rings (Fig 1b). Thus, the dianion can be described as an adamantanoid structure with four peripheral iodide groups. The dianion interacts with neighbouring $\mathrm{K} 222-\mathrm{H}_{2}{ }^{2+}$ dications in two different ways. First, three I atoms

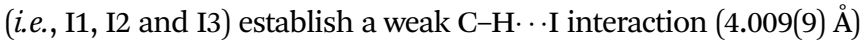
(Fig. 1c). A second type of weak interaction corresponds to $\mathrm{C}-\mathrm{H} \cdot \cdots \mathrm{O}$ (3.66(3) $\AA$ ) where the $\mathrm{H}$ atom in $\mathrm{K} 222-\mathrm{H}_{2}{ }^{2+}$ is hydrogen bonded to the coordinating oxygen in the adamantanoid cluster (Fig. 1d). The iodide (I4) atom in the upper part of the adamantanoid (a)

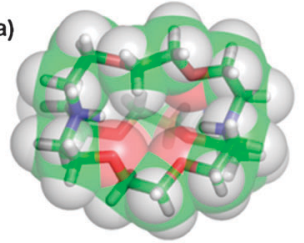

(c)

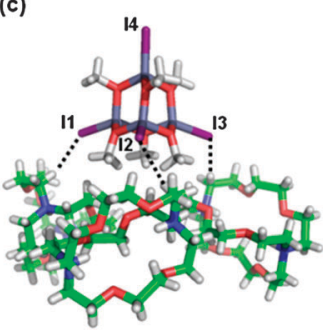

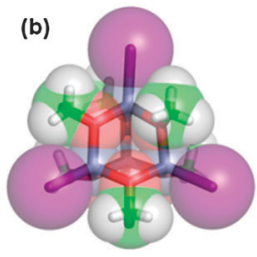

(d)

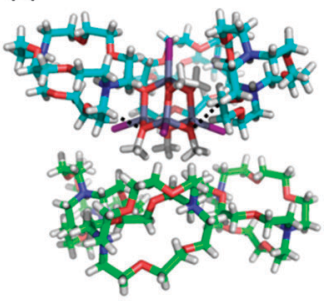

Fig. 1 Single crystal X-ray structure of complex 1. View of (a) the dication and (b) dianion. (c) Side view of the adamantanoid cluster surrounded by the dications establishing hydrogen bond interactions via $\mathrm{C}-\mathrm{H} \ldots$; (d) the same view of (c) but with the $\mathrm{C}-\mathrm{H}$...O interactions with the adjacent layer of cations. Different colours have been given to K222 for the sake of clarity. The disordered $\mathrm{H}_{2} \mathrm{O}$ molecule is not shown. cluster does not interact with any surrounding atom. Finally, the overall structure adopts an isomer $I V$ type conformation. ${ }^{9 e}$

In the mother solution, we also observed the presence of a second type of crystal together with $\mathbf{1}$. X-ray structure determination showed that this crystal (2) is isostructural to the reported trigonal $R \overline{3} c$ (167) $\mathrm{ZnCl}_{2}$ version, ${ }^{14}$ where $\mathrm{K} 222$ is also doubly-protonated and adopts the endo-endo type conformation. ${ }^{15}$ The $\left[\mathrm{ZnI}_{4}\right]^{2-}$ anions, lying in the 3-fold crystallographic axis, show tetrahedral coordination (Fig. S2, ESI $\dagger$ ). ${ }^{16}$ Interestingly, the bulk of the sample containing both types of crystals (1 and 2) was dried and ground for powder $\mathrm{X}$-ray diffraction analysis (PXRD), and the resulting powder diffraction pattern showed the presence of a single phase which corresponded to complex 2 (Fig. 2d). Puzzled by this initial finding, we considered that two options were possible: (i) complex $\mathbf{1}$ is unstable in air and transforms into 2; or (ii) the grinding process induced a mechanochemical structural transformation of 1 to 2 .

To elucidate the cause of the transformation, single crystals of 1 were mounted on a Nylon loop without using protectant oil (i.e., to allow direct exposure to air) for X-ray structural analysis. Upon indexing, the resulting unit cell was the same as $\mathbf{1}$. Then, the crystal was left in contact with air for 3 days. Single crystal X-ray structural analysis showed that $\mathbf{1}$ transformed into a polycrystalline solid whose Debye-Scherrer-like diffraction plot matches that of 2 (Fig. 2b). ${ }^{17}$ This represents the first report of a solid state transformation which might imply the release of coordinated methanol molecules and the break-up of the adamantanoid cluster going from the $\left[\mathrm{Zn}_{4}(\mathrm{MeO})_{6} \mathrm{I}_{4}\right]^{2-}$ to the $\left[\mathrm{ZnI}_{4}\right]^{2-}$ ion (Fig. 2). In the process, the dication remains virtually unchanged

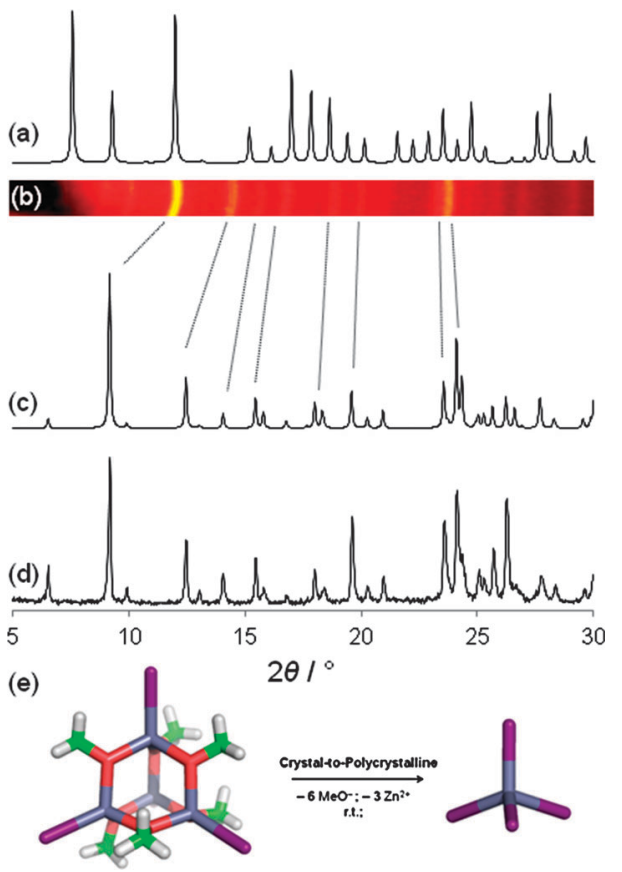

Fig. 2 Comparison between PXRD patterns of $\mathbf{1}$ and 2. (a) Simulated PXRD of 1; (b) X-ray diffraction of a single crystal of 1 exposed to air for 3 days; (c) simulated PXRD of 2; and (d) experimental PXRD of a polycrystalline sample of 1 exposed to air for 3 days and ground. (e) Cartoon depicting the solid-state transformation of $\left[\mathrm{Zn}_{4}(\mathrm{MeO})_{6} \mathrm{I}_{4}\right]^{2-}$ into $\left[\mathrm{ZnI}_{4}\right]^{2-}$ at room temperature. 
and we note that the $\mathrm{C}-\mathrm{H} \cdot \cdots \mathrm{I}$ interactions between the cations and anions (Fig. 1c and Fig. S2d, ESI $\dagger$ ) are of the same type in 1 and $\mathbf{2}$ and are somehow maintained after the transformation, suggesting their important role in the structures' stability.

Mass balance indicates that other Zn-containing species, evidently lacking crystallinity, should form in the reaction. Elemental analysis carried out on the bulk crystalline sample, after exposure to air, completely supports the occurrence of the solid-state transformation shown in Fig. $2 \mathrm{~d}$ and indicates that the final $1 / 2$ of $\mathrm{Zn}$ (II) salts is composed of $\mathrm{Zn}(\mathrm{OH})_{2}$. This implies the replacement of OMe groups with $\mathrm{OH}$ groups. ${ }^{18}$ Interested in this solid-state reaction we investigated the possibility that the adamantanoid structure could be formed with smaller halides such as bromide and chloride. Notably, under the same experimental conditions, only trigonal phases isostructural to 2 were obtained (compounds 3 and $\mathbf{4}$, see ESI $\dagger$ ). ${ }^{19}$ Hence, such solidstate transformation is possible only for the iodide case.

Similar crystallization experiments using $\mathrm{K} 222$ and $\mathrm{ZnI}_{2}$ in ethanol, instead of methanol, did not form the adamantanoid cluster, but compound 2 as shown by PXRD and single crystal $\mathrm{X}$-ray diffraction (see ESI $\dagger$ ). Furthermore, liquid assisted grinding (LAG) of the starting materials, using a drop of methanol, also resulted in the formation of 2 exclusively.

Moreover, experiments using aprotic MeCN solvent, working under similar conditions, resulted again in the formation of 2 only. As the formation of the adamantanoid cluster was not observed in the above-mentioned cases, this strongly indicates that the presence of methanol is necessary for the self-assembly of the adamantanoid cluster. However, since the protonation of $\mathrm{K} 222$ is also observed in MeCN, we speculate that atmospheric water can also act as the source of protons in the system. ${ }^{20}$

The different behaviour observed in methanol and in ethanol can be simply explained by steric factors. At variance with the S-containing adamantanoid clusters, which are able to accommodate bulky substituents, the $\mu$-O-based cluster is significantly smaller (volumes and distances between opposite $\mu-\mathrm{O}(\mathrm{S})$ atoms $382.5 \AA^{3}$ $4.32 \AA$ and $446.5 \AA^{3}-5.44 \AA$ for the $\mu-O$ and $\mu-S$ clusters, respectively $)^{21}$ and an additional carbon on the alkoxide chain would probably lead to significant steric clash with the apical I atoms.

A last comment is given on the behaviour of $\mathbf{1}$ in solution. The ${ }^{1} \mathrm{H}-\mathrm{NMR}$ spectrum of $\mathbf{1}$, shown in Fig. S11 and S12 (ESI $\dagger$ ), was recorded after dissolution of crystals of 1 , manually separated from those of 2 in the bulk, into a $2: 1$ deuterated DMSO : acetone solvent mixture. A preliminary analysis indicates that $\mathbf{1}$ is present as an $85: 15$ mixture of two species, namely the associated ion-pair and its dissociated form. The presence of singlet signals around $3.2 \mathrm{ppm}$, assigned to the $\mu$-OMe groups, and the comparison with the spectrum of an equimolar solution of 2 strongly support the survival of the anionic adamantanoid structure of 1 under the investigated circumstances (Fig. S13 and S14, ESI $\dagger$ ).

In summary, we have synthesized and characterized a new complex which displays an adamantanoid-type structure and a peculiar solid state reactivity. Although literature on salts composed of adamantane-like dianions of formulae $\left[(\mu-\mathrm{SR})_{6}(\mathrm{MSR})_{4}\right]^{2-}$, $\left[(\mu-\mathrm{SR})_{6}(\mathrm{MSR})_{4-n},(\mathrm{MX})_{n}\right]^{2-}$ or $\left[(\mu-\mathrm{SR})_{6}(\mathrm{MSR})_{4-n}(\mathrm{ML})_{n}\right]^{n-2}(n=1-4$; $\mathrm{X}=\mathrm{Cl}, \mathrm{Br}$ and $\mathrm{I} ; \mathrm{L}=$ neutral solvent; $\mathrm{M}=\mathrm{d}$-block metal, $\mathrm{R}=$ alkyl, aryl) is rich, ${ }^{9}$ to the best of our knowledge, structure 1 contains the first $\mu$-oxo adamantanoid cluster. ${ }^{10}$ The process of formation of 1 was never described before and, notably, it was found to be specific for iodide, since bromide and chloride $\mathrm{Zn}$ salts formed only isostructural $\mathrm{ZnX}_{4}{ }^{2-}$ type of material 2 (and 3-4, see $\mathrm{ESI} \dagger$ ). An unusual solid-to-solid process which affords 2 by exposing 1 to air and which involves the break-up of the adamantanoid cluster was also observed and described.

The study of the properties of non-centrosymmetric 1 in the solid state, in relation to non-linear optical applications, and in solution is currently on-going.

\section{Experimental}

\section{General}

All the reagents and solvents were purchased from Sigma Aldrich and used without further purification. All single crystals used for X-ray analysis were checked using a Leica M165 C microscope equipped with a cross polarizer. ${ }^{1} \mathrm{H}$-NMR spectra were recorded using a $500 \mathrm{MHz}$ Bruker spectrometer at $25{ }^{\circ} \mathrm{C}$.

\section{X-ray diffraction data}

Single crystal X-ray diffraction data for 1, 2 and 3 were recorded using a Bruker X8 Prospector APEX-II/CCD diffractometer equipped with an Incoatec $\mathrm{I} \mu \mathrm{S}_{\mathrm{Cu}}$ microfocus X-ray source $\left(\mathrm{CuK}_{\alpha}\right.$ radiation, $\lambda=1.54056 \AA$ ) and with a CCD detector. The low temperature experiments were collected using a Bruker Oxford Cryosystem device. SHELXL ${ }^{22}$ was used for structure solution and refinement. X-ray powder diffraction experiments were recorded on a Bruker D2 Phaser diffractometer $(\lambda=1.54056 \AA)$. The $2 \theta$ scan range was $4.7-40^{\circ}$ with a step size $0.02^{\circ}$. The exposure time was $2 \mathrm{~s}$. Simulated PXRD patterns were generated using Mercury Version 3.1 software program. Figures depicting the crystal packing were created using PyMol software.

\section{Notes and references}

$\ddagger$ Single crystal X-ray diffraction data for $1: \mathrm{C}_{24} \mathrm{H}_{58} \mathrm{I}_{4} \mathrm{~N}_{2} \mathrm{O}_{12} \mathrm{Zn}_{4}, M_{\mathrm{r}}=$ 1335.8, crystal dimensions $0.13 \times 0.07 \times 0.06 \mathrm{~mm}^{3}$, cubic, space group, $P 2{ }_{1} 3$, unit cell, $a=16.3228(18) \AA, V=4348.9(8) \AA^{3}, T=100(2) \mathrm{K}, Z=4$, Anisotropic least-squares refinement (148 parameters) on 2127 independent merged reflections $\left(R_{\text {int }}=0.0354\right)$ converged at $\mathrm{w} R_{2}\left(|F|^{2}\right)=$ 0.0718 for all data; $R_{1}(F)=0.0316$ for 1972 observed data $(I>2 \sigma(I))$, $\mathrm{GOF}=1.072$. Single crystal X-ray diffraction data for 2: $\mathrm{C}_{18} \mathrm{H}_{40} \mathrm{I}_{4} \mathrm{~N}_{2} \mathrm{O}_{6.17} \mathrm{Zn}_{1}$, $M_{\mathrm{r}}=956.16$, crystal dimensions $0.13 \times 0.11 \times 0.02 \mathrm{~mm}^{3}$, trigonal, space group, $R \overline{3} c$, unit cell, $a=11.4410(7) \AA, b=11.4410(7) \AA, c=$ 81.313(6) $\AA, V=9217.6(11) \AA^{3}, T=296(2) \mathrm{K}, Z=12$, Anisotropic leastsquares refinement (100 parameters) on 1797 independent merged reflections $\left(R_{\text {int }}=0.0901\right)$ converged at $\mathrm{w}_{2}\left(|F|^{2}\right)=0.1760$ for all data; $R_{1}(F)=$ 0.0617 for 1620 observed data $(I>2 \sigma(I))$, GOF $=1.127$.

1 (a) G. M. H. Schmidt, Pure Appl. Chem., 1971, 27, 647; (b) K. Tanaka and F. Toda, Chem. Rev., 2000, 100, 1025; (c) G. K. Kole and J. J. Vittal, Chem. Soc. Rev., 2013, 42, 1755; (d) P. Naumov, Chemical X-Ray Photodiffraction: Principles, Examples, and Perspectives, Top. Curr. Chem., 2012, 315, 111; (e) D. de Loera, A. Stopin and M. A. Garcia-Garibay, J. Am. Chem. Soc., 2013, 135, 6626; $(f)$ L. Meazza, J. Martí-Rujas, G. Terraneo, C. Castiglioni, A. Milani, T. Pilati, P. Metrangolo 
and G. Resnati, CrystEngComm, 2011, 13, 4427; (g) M. Garai, R. Santra and K. Biradha, Angew. Chem., Int. Ed., 2013, 52, 5548; (h) J. Martí-Rujas and M. Kawano, Acc. Chem. Res., 2013, 46, 493; (i) T. Seki, K. Sakurada and H. Ito, Angew. Chem., Int. Ed., 2013, 52, 12828; ( $j$ ) J. Martí-Rujas, L. Meazza, G. K. Lim, G. Terraneo, T. Pilati, K. D. M. Harris, P. Metrangolo and G. Resnati, Angew. Chem., Int. Ed., 2013, 52, 13444; ( $k$ ) J. K. Sun, B. Tan, L. X. Cai, R. P. Chen, J. Zhang and J. Zhang, Chem.-Eur. J., DOI: 10.1002/chem.201303700; (l) G. K. Kole, T. Kojima, M. Kawano and J. J. Vittal, Angew. Chem., Int. Ed., 2014, 126, 2175-2178.

2 (a) K. T. Holman, A. M. Pivovar and M. D. Ward, Science, 2001, 294, 1907; (b) D. A. Beauchamp and S. J. Loeb, Chem.-Eur. J., 2002, 8, 5084; (c) D. S. Reddy, S. Duncan and G. K. H. Shimizu, Angew. Chem., Int. Ed., 2003, 42, 1360; (d) M. W. Hosseini, Acc. Chem. Res., 2005, 38, 313; (e) D. J. Mercer and S. J. Loeb, Chem. Soc. Rev., 2010, 39, 3612.

3 S. A. Dalrymple and G. K. H. Shimizu, J. Am. Chem. Soc., 2007, 129, 12114.

4 Z. Liu, M. Frasconi, J. Lei, Z. J. Brown, Z. Zhu, D. Cao, J. Iehl, G. Liu, A. C. Fahrenbach, Y. Y. Botros, O. K. Farha, J. T. Hupp, C. A. Mirkin and J. F. Stoddart, Nat. Commun., 2013, 4, 1855.

5 E. Coronado, M. Giménez-Marqués, G. Mínguez Espallargas and L. Brammer, Nat. Commun., 2012, 3, 828.

6 (a) G. M. Espallargas, L. Brammer, J. van de Streek, K. Shankland, A. J. Florence and H. Adams, J. Am. Chem. Soc., 2006, 128, 9584; (b) C. J. Adams, M. F. Haddow, M. Lusi and A. G. Orpen, CrystEngComm, 2011, 13, 4324.

7 F. Guo, H.-d. Shao, Q. Yang, A. Famulari and J. Martí-Rujas, CrystEngComm, 2014, 16, 969.

8 (a) L. R. MacGillivray and J. L. Atwood, Chem. Commun., 1996, 735; (b) L. R. MacGillivray and J. L. Atwood, Angew. Chem., Int. Ed. Engl., 1996, 35, 1828; (c) L. R. MacGillivray and J. L. Atwood, J. Am. Chem. Soc., 1997, 119, 2592.

9 (a) I. G. Dance, Inorg. Chem., 1981, 20, 2155; (b) P. A. W. Dean, J. J. Vittal and N. C. Payne, Inorg. Chem., 1987, 26, 1683; (c) P. A. W. Dean, J. J. Vittal and Y. Wu, Inorg. Chem., 1994, 33, 2180; (d) H.-O. Stephan and G. Henkel, Polyhedron, 1996, 15, 501; (e) P. A. W. Dean, N. C. Payne, J. Wranich and J. J. Vittal, Polyhedron, 1998, 17, 2411; $(f)$ X. Zhang, Y. Tian, F. Jin, J. Wu, Y. Xie, X. Tao and M. Jiang, Cryst. Growth Des., 2005, 5, 565; (g) J.-B. Jiang, G.-Q. Bian, Y.-P. Zhang, W. Luo, Q.-Y. Zhu and J. Dai, Dalton Trans., 2011, 40, 9551; (h) X.-Y. Tang, R.-X. Yuan, J. X. Chen, W. Zhao, A. X. Zheng, M. Yu, H.-X. Li, Z.-G. Ren and J.-P. Lang, Dalton Trans., 2012, 41, 6162; (i) R. Stieler,
F. Bublitz, E. Schulz Lang and G. M. de Oliveira, Polyhedron, 2012, 31, 596.

10 There actually exists a report on a $\operatorname{Zr}(\mathrm{IV})$ adamantanoid complex whose X-ray structure is not reported. The octahedral coordination of the $\operatorname{Zr}(\mathrm{Iv})$ metal centre shows a distinctive difference; see P. Sobota, S. Przybylak, J. Utko and L. B. Jerzykiewcz, Organometallics, 2002, 21, 3497.

11 We note that 1 appears together with another crystal phase with different habits (later labelled 2).

12 We refined an $\mathrm{O}$ assigned to a water molecule located at a special position (i.e., 3-fold axis) with an occupancy factor of $30 \%$.

13 B. Metz, D. Moras and R. Weiss, J. Chem. Soc., Perkin 2, 1976, 423.

14 Isostructural salt complexes crystallizing in the trigonal space group $R \overline{3} c$ have been obtained upon evaporation of a mixture of $\mathrm{K} 222$ and $\mathrm{MnCl}_{2}$ or $\mathrm{ZnCl}_{2}$ in strongly acidic (HCl) aqueous ethanol. See: A. N. Chekhlov, Russ. J. Coord. Chem., 2007, 33, 932.

15 The acidic conditions serve the purpose of protonating the cryptand and availing the formation of the $\left[\mathrm{M}(\mathrm{Cl})_{4}\right]^{2-}$ dianion ( $\mathrm{M}=\mathrm{Zn}, \mathrm{Mn}$ ) in solution. So far, many of the complex salts reported were crystallized using the chloride anion, a far better hydrogen bond (HB) acceptor than bromide and iodide, while the synthesis of salts containing K222 and other non-chlorometallates has received less attention.

16 The X-ray crystallographic analysis revealed that the water molecule observed is disordered and can be only refined with reasonable thermal parameters if the occupancy factor is $17 \%$.

17 One $\varphi \operatorname{scan}\left(360^{\circ}\right)$ at $2 \theta=0^{\circ}$ was recorded at room temperature. The exposure time was $900 \mathrm{~s}$. The crystal-to-detector distance was $50 \mathrm{~mm}$.

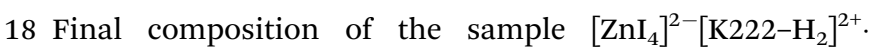
$\mathrm{Zn}(\mathrm{OH})_{2}$; found: $\mathrm{C}=20.08 ; \mathrm{H}=3.74 ; \mathrm{N}=2.74$. Calcd: $\mathrm{C}=20.57 ; \mathrm{H}=3.84 ; \mathrm{N}=2.67$.

19 We also explored the possibility of inducing the formation of kinetic products by performing the reaction with $\mathrm{ZnBr}_{2}$ and $\mathrm{ZnCl}_{2}$ at lower temperatures (i.e., $0{ }^{\circ} \mathrm{C}$ ): 3 and 4 invariably formed. J. Martí-Rujas, Y. Matsushita, F. Izumi, M. Fujita and M. Kawano, Chem. Commun., 2010, 46, 6515. 20 (a) P. Auffinger and G. Wipff, J. Inclusion Phenom., 1991, 11, 71; (b) L. R. MacGillivray and J. A. Atwood, J. Org. Chem., 1995, 60, 4972.

21 Based on $a b$ initio calculations on the adamantanoid dianion of formula $\left[\mathrm{Zn}_{4}(\mathrm{MeO})_{6} \mathrm{I}_{4}\right]^{2-}$ and $\left[\mathrm{Zn}_{4}(\mathrm{MeS})_{6} \mathrm{I}_{4}\right]^{2-}$ at the HF-3-21G level (see ESI $\dagger$ ).

22 G. M. Sheldrick, Acta Crystallogr., Sect. A: Fundam. Crystallogr., 2008, 64, 112. 